This item was submitted to Loughborough's Research Repository by the author.

Items in Figshare are protected by copyright, with all rights reserved, unless otherwise indicated.

\title{
Resilience strategies of healthcare facilities: present and future
}

PLEASE CITE THE PUBLISHED VERSION

http://dx.doi.org/10.1108/17595901011080869

PUBLISHER

(c) Emerald Group Publishing Limited

VERSION

AM (Accepted Manuscript)

LICENCE

CC BY-NC-ND 4.0

REPOSITORY RECORD

Achour, Nebil, and Andrew D.F. Price. 2019. "Resilience Strategies of Healthcare Facilities: Present and Future". figshare. https://hdl.handle.net/2134/8852. 
This item was submitted to Loughborough's Institutional Repository (https://dspace.lboro.ac.uk/) by the author and is made available under the following Creative Commons Licence conditions.

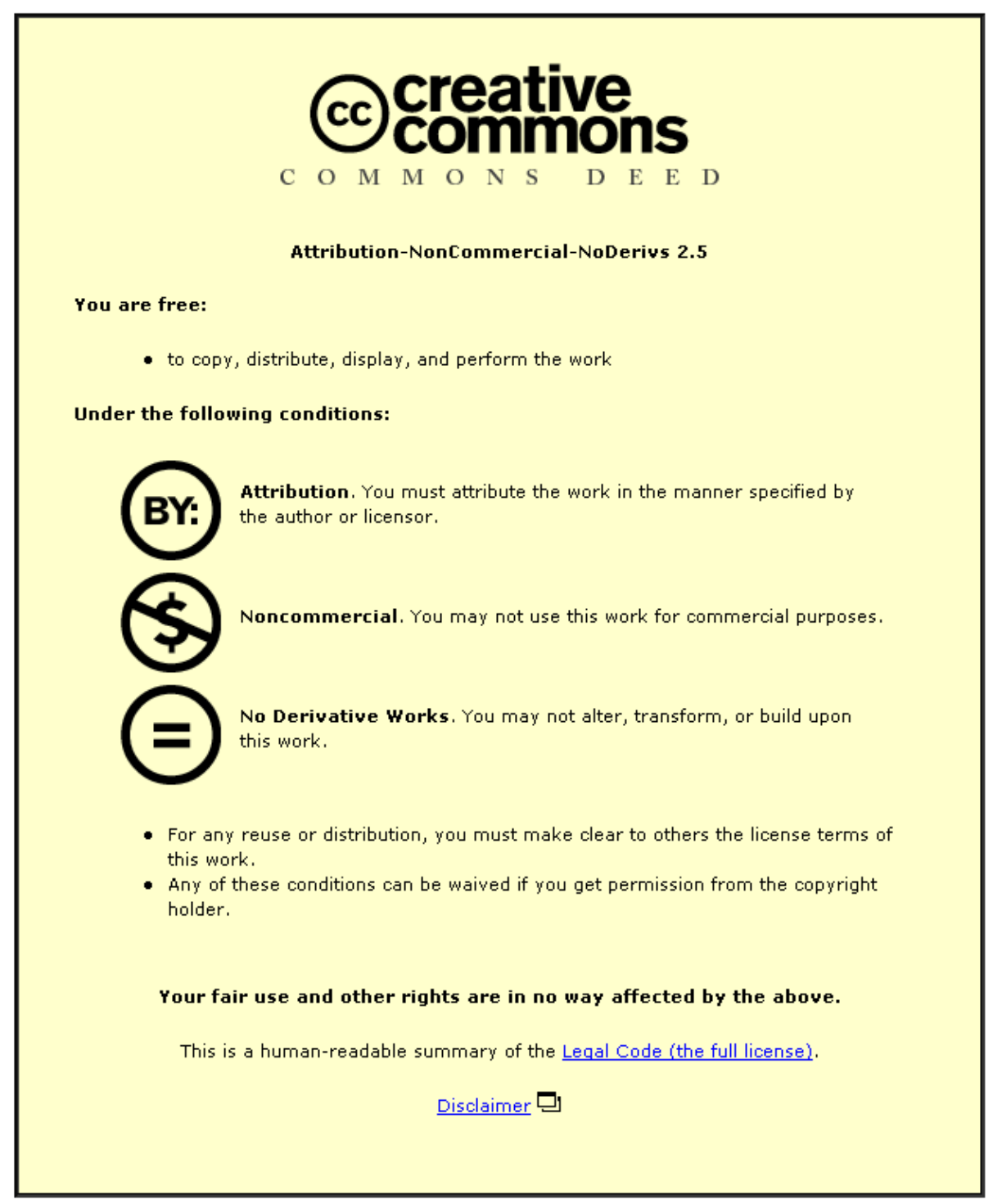

For the full text of this licence, please go to: http://creativecommons.org/licenses/by-nc-nd/2.5/ 


\title{
Resilience Strategies of Healthcare Facilities: Present and Future
}

\author{
Nebil Achour \\ Department of Civil and Building Engineering, Loughborough University, UK \\ Andrew D F Price \\ Department of Civil and Building Engineering, Loughborough University, UK
}

\section{Purpose:}

The purpose of this paper is to explore UK healthcare resilience strategies; define gaps and provide suggestions based on international best practice.

\section{Design/methodology/approach:}

The study adopted a pluralistic qualitative research approach to achieve its purpose including: research papers, governmental and non-governmental reports, code and guidance documents, and databases. In addition, two case studies were visited in May 2009: the first was one of the major hospitals in the UK; and the second is a major health facility located at the south of Taiwan. Semi-structured interviews were conducted with the hospitals responsible and/or emergency officers to clarify the strategies setup to respond to emergencies.

\section{Findings:}

The results show that despite the "robust" emergency planning in the UK, many issues could have been avoided if international experience was reviewed carefully. This is due to the failure of not working closer with multi-disciplinary experts, who provide technical and tactical help and lessons learned from international best practices, in addition to limiting accessibility of experts to information. The study also suggests that climate change must be addressed comprehensively through fusing resilience and sustainability strategies into a more comprehensive strategy of adaptation.

\section{Originality/value:}

The paper provides a significant contribution in terms of reducing the fragmentation of healthcare resilience related work done previously; constructive criticism of UK healthcare resilience strategies; and evidence of better practice from local and international facilities which will help in enhancing the resilience of healthcare facilities in the UK and elsewhere in the world.

Keywords: healthcare, natural disaster, vulnerability, resilience, climate change 


\section{Introduction}

\subsection{Background}

A disaster can be defined as "a serious disruption of the functioning of society, causing widespread human, material or environmental losses which exceed the ability of affected society to cope using only its own resources" (UNDP India, 2008). Disasters vary according to their origins, however, they are often classified as natural or technological (CRED, 2008) and "are not always singular or isolated events" (EEA, 2003). Events in recent years have highlighted a number of risks that have to be considered when considering healthcare resilience and developing appropriate response strategies. The 2010 Port au Prince Earthquake (Haiti), the 2004 Indian Ocean Tsunami, the 2007 summer floods (UK), the 2008/9 war on Gaza and the 2009 pandemic Swine Flu have illustrated: the different types of risks; their relevant impact on health and healthcare, which services are not always available when they were needed the most. "There are countless examples of health infrastructure - from sophisticated hospitals to small but vital health centres - that have suffered this fate. One such case occurred in the Hospital Juarez in Mexico. In 1985, almost 600 patients and staff lost their lives when this modern (for its time) and well-equipped hospital collapsed in the wake of an earthquake" (WHO, 2007). This paper aims to: explore UK healthcare resilience strategies, define gaps and provide suggestions based on international best practice.

\subsection{Significance and complexity of healthcare facilities}

Healthcare is often thought of as an elaborate network of buildings and services that collaborate in an efficient way to provide the general public the service they have come to expect; this collaborative working is known as a healthcare system. The healthcare system represents one of the most complicated and critical emergency response resources in any country, along with facilities such as fire departments and police stations; however, healthcare facilities have particular importance as they will be central to dealing with the large number of injuries typically associated with large-scale disasters. The Pan American Health Organization (PAHO, 2000) described a hospital as "a hotel, an office building, a laboratory and a warehouse" (p.12) due to the complexity and interconnectivity of its systems which is the main reason for its fragility. A typical healthcare facility depends on: the state of its building (e.g. structural and architectural elements and utilities); availability and sufficiency of staff, equipment, space and medical supply; and easy accessibility (e.g. roads) for its daily operation. Any damage or malfunction of any of these elements will have direct, or indirect, impact on the continuity of medical services. Modern hospitals and healthcare trusts also offer much more than the medical care that the general public expects. They play a huge role in preventative medicine and host public health laboratories and health research centres (PAHO, 2009). There is an increasing interest in developing new and 'better' healthcare service by adopting new approaches such as 'Telecare', 'Telehealth' and 'Care Closer to Home' which will increase the complexity of healthcare service and impact on resilience.

\subsection{Healthcare resilience and linkage with sustainability}

Increased technological capability has resulted in many power dependant systems and extensive use of monitors, heating ventilation, air conditioning (HVAC) and artificial lighting systems, in addition to energy inefficient buildings that have emitted significant amounts of carbon dioxide $\left(\mathrm{CO}_{2}\right)$. Consequently, the environment has deteriorated and caused global warming and the climate to change. More extreme weather events such as floods, heat waves and gales are expected, and even more earthquakes are to occur (Chalko, 2001, Hetzel and Hampel, 2006). "The observed 5-fold increase in annual earthquake energy in the period 1980-2007 and the rapidly increasing trend are 
alarming. Results indicate that the main danger for humanity on Earth may come not from a slow climate change, but from the rapidly increasing seismic/tectonic activity" (Chalko, 2008). Although there is a debate between researchers about the effect of climate change on seismic activities, there is no doubt that both, Hydrometeorological and geophysical, hazards have the potential to cause significant disruption to societies and thus there is a need to set appropriate strategies to mitigate their impact.

In line with the UK government's commitment to radically reduce $\mathrm{CO}_{2}$ emissions, there is a growing need to design low carbon services to reflect the changing lifestyles associated with low carbon living. The National Health Service (NHS) is a major contributor to climate change and as the largest user of energy on the Government Estate; consuming 45MGJs of energy and emitting one million tonnes of carbon per year, most of which is due to buildings and health transport activities (DH, 2008a). Consequently, the Department of Health (DH, 2008b) has been committed to reduce $\mathrm{CO}_{2}$ emission, in order to: preserve the environment; reduce the contribution to climate change.

With its effects set to exacerbate the disaster situation, the NHS has recognised the need, and is taking action to not only increase the robustness of emergency planning, but also reduce its energy and carbon efficiency whilst still striving to improve health service provision. There is significant number of publications that illustrate the NHS's strategy for dealing with sustainability and resilience issues; however, there is a lack of guidance and strategies to link these two issues although previous research has recognised "the close interrelationship between disaster reduction and sustainable development, which was already recognized at the United Nations Conference on Environment and Development and taken into account in Agenda 21" (UN General Assembly, 1994); and Mileti (1999) stated that a "community that wants to become more sustainable will: maintain and, if possible, enhance, its residents' quality of life; enhance local economic vitality; ensure social and intergenerational equity; maintain and, if possible, enhance, environmental quality; incorporate disaster resilience and mitigation; and use a consensus-building, participatory process when making decisions". Climate change should be addressed by fusing resilience and sustainability strategies into a more comprehensive strategy of adaptation that is able to: reduce contribution to global warming and climate change (i.e. reduction of $\mathrm{CO}_{2}$ ); and cope with extreme environmental impacts (see Figure 1).



Figure 1: Build in resilience by adaptation 


\subsection{Methodology}

This study adopts a qualitative approach to explore and understand the various parameters that the resilience of healthcare facilities depends on; and the required actions to mitigate risks. An extensive and various amount of previous research outcomes were investigated including: research papers, governmental and non-governmental reports, code and guidance documents, and databases such as EM-DAT (2008). In addition, two case studies were visited in May 2009: the first was a major hospital in the UK (name has been kept confidential as per facility request); and the second is a major health facility located at the south of Taiwan. Semi-structured interviews were conducted with the hospitals responsible and/or emergency officers to clarify the strategies setup to respond to emergencies.

\section{Risk identification}

Controversially, the risk and the impact of manmade disasters have not been as significant as natural disasters such as floods; however, considerable attention is being given to the former, specifically in terms of expenditure (see Table 1). The inadequate preparedness of the UK government to natural disasters and poor performance of infrastructure components in recent years pressed the Cabinet Office (2010) to develop and release the Strategic Framework and Policy Statement on Improving the Resilience of Critical Infrastructure to Disruption from Natural Hazards document, thus highlighting the need for further research into: natural disasters; their impact on health and healthcare; and infrastructure components.

National priorities change frequently on the UK Resilience homepage; however, floods and diseases and/or infections feature regularly on the list. Floods can: result in infections and diseases; cause injuries; and physically affect healthcare infrastructure. Previous research suggests that there is a similarity between the impact of floods and the impact of other natural disasters; for example, Ahern and Kovats (2006) and Hamilton et al. (2009) stated that floods cause mental health problems, skin injuries and fractures, which was found previously as a result of earthquakes by many researchers such as Gunn (1995), Sharma (2002) and Zhang et al. (2009). This study, therefore, will not be limited to floods but also to other natural disasters in order to draw a comprehensive picture of healthcare resilience.

Table 1: Floods and political conflict on the UK and expenditure (1900-2008)

\begin{tabular}{|c|c|c|c|c|}
\hline \multirow{2}{*}{ Disaster type } & \multicolumn{2}{|c|}{ Disasters in $2000-2007$} & \multirow{2}{*}{$\begin{array}{l}\text { Total losses (Billion } \\
\text { Pound Sterling- £B) }\end{array}$} & \multirow{2}{*}{$\begin{array}{c}\text { Budget allocated }- \text { in } \\
£ B\end{array}$} \\
\hline & Total \# & Affected people & & \\
\hline $\begin{array}{l}\text { Political conflict } \\
\text { (terrorism) }\end{array}$ & 25 & 1,011 & No available data & $\begin{array}{c}1(2001) \\
2.5(2007 / 8) \\
3.5(2010 / 11) \\
\end{array}$ \\
\hline Floods & 14 & $395,000<$ & $9.1<$ & $\begin{array}{c}0.6(2007 / 8) \\
0.8(2010 / 11) \\
\end{array}$ \\
\hline
\end{tabular}

\section{Healthcare facilities performance post disasters}

\subsection{Case of the UK}

Recent extreme weather events have severely affected UK healthcare facilities. The snowfall of early and late 2009 demonstrated the vulnerability of UK healthcare: although snowfall does not cause as many injuries/patients as other disasters, healthcare facilities were stretched to their limits, experienced lack of staff, and had to cancel many outpatient services. Many outpatient appointments were cancelled to "devote maximum resources to keeping emergency services running after heavy 
snowfall" in January 2009 (Carvel, 2009); and to reduce the pressure on facilities specifically those with low staff attendance: some nurses "had six hour journeys home, and others stayed the night at hospital to ensure they could be at work" in December 2009 (Moore, 2009). Unfortunately, there is limited amount of information about the performance of healthcare facilities; the difficulties faced by medical staff; and the strategies adopted to mitigate the impact on medical services. The Report on the lessons learned from the summer 2007 flooding experiences, from an Estates and Facilities perspective (DH, 2008c) highlights several weaknesses faced in many hospitals. They are related to:

- interruption of utilities supply including contamination and shortage of water (unavailability of alternative sources) and lack of electric power and telecommunication (engaged lines);

- isolation of facilities and interruption/cancellation of medical services;

- inaccessibility to facilities;

- inappropriate coordination between facilities and suppliers;

- $\quad$ staffing problems (specifically contractors from private sector); and

- inadequate staff facilities on hospital sites.

Furthermore, the Pitt Review (2008) identified problems, not highlighted by the DH report, such as failing to include the number of people reporting to healthcare professionals with physical and psychological health problems caused by flooding. An in depth and independent investigation post disasters and extreme weather events is thus required to provide evidence for resilience strategies and create opportunities for further research.

\subsection{International case}

"It is almost always the case that, when struck by large-scale natural disasters, hospital services are interrupted temporarily or permanently, mainly due to damage to their infrastructure" (PAHO, 2004) or external infrastructure components that they depend on to operate. The 1993 Midwest floods caused lack of "potable water needed to maintain essential patient care activities", loss of electric power and telephone communication (Peters, 1996). International health organisations such as WHO, PAHO and others recommended that healthcare facilities have alternative suppliers and duplicate items to provide a certain level of independence from external supply networks (PAHO, 2000). Consequently, many hospitals were equipped with alternative supply networks, which increased their resilience and helped in the continuity of medical services; however, the inappropriate choice of equipment and the interdependency between systems caused disruption and even evacuation of facilities. For example, the weakness of the electric power generator in the Ishimaki Emergency Center (Japan) caused the X-ray service to halt (Achour, 2007); the loss of electric power in the Tohoku Koseinenkin Hospital (Japan) caused a shortage of water that needs filtering; and the shortage of water caused the emergency power generators to switch off (fear of overheating), which in turn caused the closure of the Kobe Medical College (Japan) after the 1995 Kobe Earthquake (Shinozuka et al., 1995).

Inaccessibility is frequently a major problem following most natural disasters: earthquakes often demolish buildings which results in a narrowing of roads; and flood water submerge roads such as in the cases of the Ben Taub General Hospital and the Texas Medical Center, both of which experienced reduced accessibility during the 2001 Huston Flood due to flooded roads (Sirbaugh et al., 2002). "The annual precipitation in Japan is twice as high as the world average" and "the typhoon season always bring torrential rainstorms that cause severe flood damages throughout the country" (JSWA, 2002), consequently, the Japanese authorities expanded and developed their sewage and storm water system, and set four challenges that "must meet new needs from citizens in Japan by 1) bringing about clean water environment, 2) creating flood-resistant cities, 3) building recycle-based societies, and 4) realizing and maintaining comfortable sewerage services" (JSWA, 2002). This demonstrates that inaccessibility is a composed problem of different authorities; healthcare authorities are not expected to strengthen the city draining system, but they are expected to carefully select the location of new facilities and take preventative measures for existing facilities. It also demonstrates that healthcare 
facility resilience is a complex problem related to national infrastructure preparedness. Extreme weather events tend to have a greater impact on countries which are often unprepared, thus resulting in significant interruption of services, whilst well-prepared countries tend to suffer minor disruptions and manage to maintain most services, for example, the 2009/10 snowfall almost paralysed many countries in Europe such as the UK and Ireland, whilst such levels are common in countries such as Japan, Russia and Canada.

\section{Internal strategies for healthcare resilience}

\subsection{Case of the UK (Case Study 1)}

Case Study 1 was classified as Category 1 according to the Civil Contingencies Act (CCA) 2004 making it at the front line of emergency responders. This requires it to develop, maintain and test business continuity plans to ensure that core services can function throughout an emergency. The hospital is located in an area susceptible to flooding from two riverine sources each with their own unique flood characteristics. Two flood scenarios were developed for the facility. Scenario 1 is fast rising, it subsides quickly resulting in a short contact time with the facility South Bloc; this means that the velocity of water will be high, creating the perfect situation for debris flow impact and posing risk to movable objects. Scenario 2 is slow rising, which leads to much longer contact time with the hospital and affects both South and East blocks. A large part of the city is expected to be flooded before the hospital which produces debris flow, contamination and sewage overflow.

The facility is well equipped with alternative sources for most utility supplies; Figure 2 illustrates the water and electric power supplies tree. Although considerable thought was given to cooling systems (fan system), some of the power generators are hosted in masonry rooms located in a floodplain area. These two rooms require further investigation as their structures, walls and floors may not perform well due to specific phenomena such as buoyancy. Investigation, however, should first consider the importance of these generators and the impact of their inoperability on the continuity of medical care.

The facility is still developing its Business Continuity Management (BCM) plans (a plan for every department/ward) as the law requires. There are some areas well in advance of the planning stages; however, in many cases where plans did exist, they were often out of date or unsuitable. The complexity of the facility and the number of issues considered in the plans demonstrate the effort exerted and reflect the complexity of the plans; however, in some parts, the actions are not clear to readers, which may mislead the applicants in time of emergencies when brevity and clarity are essential. They cover issues related to: systems failures (e.g. loss of staff, IT and telephony, utilities and buildings); flooding/severe weather; and infectious diseases. The adopted policy includes: (1) assessing the risk; (2) communicating the risk with the relevant service; (3) taking action to reduce the impact of that risk; and (4) preparing for recovery. The policy is generic and barely linked to any specific scenario, which weakens it and exposes it to failure in case of major disasters or failure of many systems simultaneously. The facility is urged to benefit from the scenarios that it holds and the experience of other facilities to identify the potential impact of floods and address them briefly, clearly and concisely in its BCM.

\subsection{International case (Case Study 2)}

Kaohsiung Municipal Min-Sheng Hospital is a major hospital in Kaohsiung city (south of Taiwan). It was flooded once in 2001 and could not accept patients for three days and lost 500,000 patient records. The facility had a strategic plan for emergencies which was built on previous experiences. Emergency plans were divided into chapters; each chapter dealt with specific disasters where the main concerns are highlighted and actions were given to help individuals before, during and post disasters. 
Actions and recommendations are brief, yet clear and concise; for example, personnel are asked to constantly check the functionality of flooding gates and draining systems (ordinary situation), and to start sourcing for water in case of flooding (see Figure 3). In the case of a typhoon and before it hits, a strategic emergency team is charged with following the typhoon's trajectory and dealing with the potential emergency that may arise. The plan does not take into consideration the facility's social resilience; however, the superintendent stated that they need to build stronger links with industry to ensure "immediate attention" in disasters.

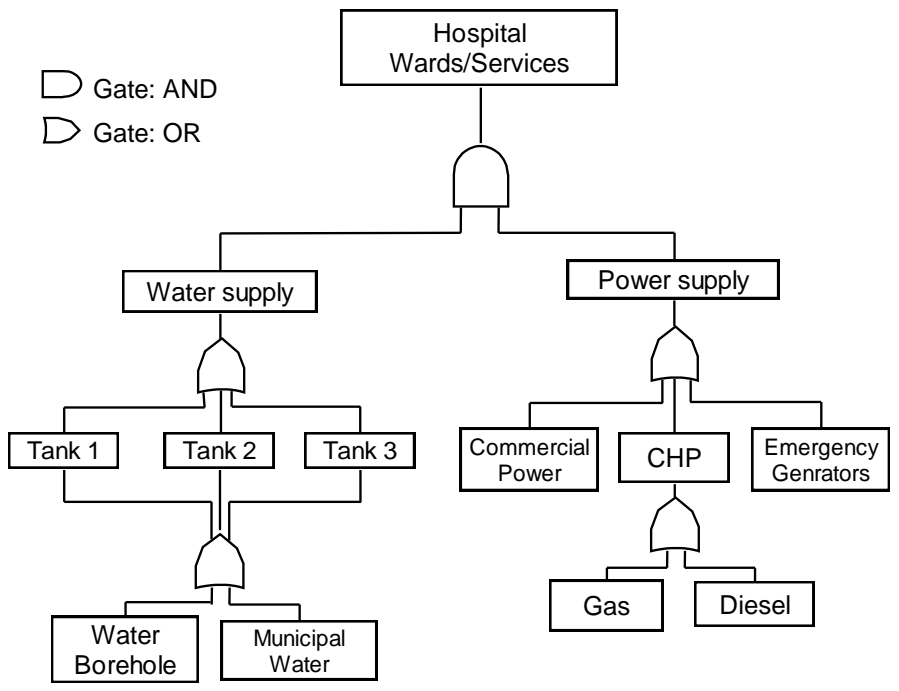

Figure 2: Water and electric power supplies tree for Case Study 1

\section{UK resilience strategy and emergency response}

"History repeats itself and teaches us. We should take heed and learn its lessons" (Jacoby, 1996).

Despite the diversity of causes and the specifics of the two case studies, disasters impact on healthcare facilities tends to be the same, i.e. discontinuity of medical services. Two key factors were identified through the investigation which have been discussed within this section and benchmarked with international practice.

\subsection{Strategy}

"The aim of business continuity management is to ensure that NHS organisations are able to maintain the highest level of service possible whatever might happen to the infrastructure" (DH, 2005), and that "managerial and clinical leadership and accountability, as well as the organisation's culture, systems and working practices ensure that probity, quality assurance, quality improvement and patient safety are central components of all the activities of the health care organisation" (DH, 2004). Although these goals are 'common' worldwide, the route leading to them varies between cases: whilst, the UK tend to follow a "generic approach", as stated by an interviewee, despite the specific disasters (e.g. fire) targeted in some documents other countries such as Japan, Taiwan and the USA tend to base their strategy on previous experiences and scenarios (i.e. modelling and simulation). The long history of storms and floods in Taiwan has forced the Kaohsiung Municipal Hospital to develop an effective strategy; for example, the strategy recognises the importance of water in floods and thus has a specific section related to water sourcing. 


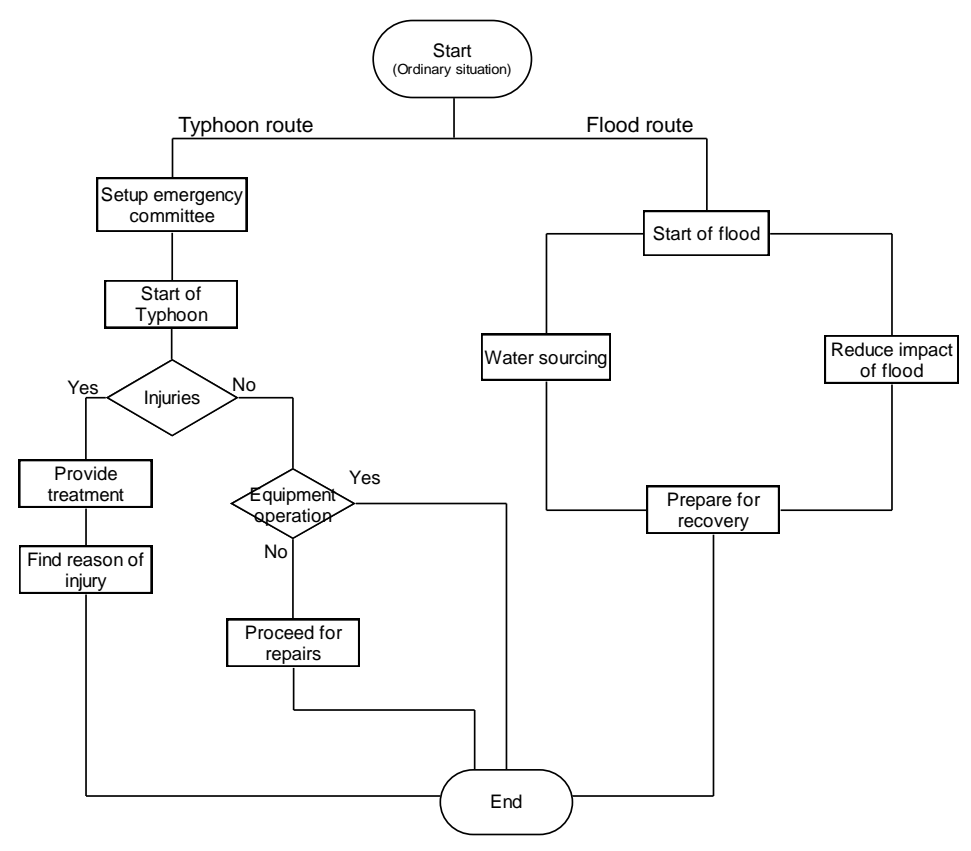

Figure 3: Flood and typhoon response strategy for Case Study 2

The UK strategy, due to previous explosions, the considerable number of security cameras, and the high allocated budget to political conflicts, demonstrates a security approach which has affected healthcare strategies on account of the focus of Department of Health guiding documents. The Health Building Notes (HBN) and the Healthcare Technical Memoranda (HTMs) provide an important set of information for engineers to improve the resilience of healthcare facilities. These vital documents provide standard guidance for day-to-day safe and secure operation. Security (i.e. manmade risks) and fire have been identified and clearly addressed in HBN 00-07 and HTM 05-03; whilst, risks associated with natural hazards (e.g. floods and snowfall) were not identified and therefore not mitigated. This failure resulted in several problems that were "unforeseen" as described by the Department of Health (2008c) Report on the lessons learned from the summer 2007 flooding experiences, from an Estates and Facilities perspective; therefore, there is a need to: carry out independent investigation of recent floods and snowfall impact on medical services continuity; and use scenarios to model and simulate previous and potential extreme weather events. This will help to identify unforeseen weaknesses; and develop the right strategies and plans to respond to similar cases. The impact of recent extreme weather events on the infrastructure (e.g. motorways and hospitals) has encouraged the government to draft the Strategic Framework and Policy Statement on Improving the Resilience of Critical Infrastructure to Disruption from Natural Hazards (Cabinet Office, 2009). The Department of Health should benefit from this document and the multi-disciplinary driven strategies to improve the resilience of NHS trusts.

The UK is way behind the USA in terms of healthcare resilience related publications. Most of American project findings, codes and guidance are available online, which helps experts and nonexperts, nationally and internationally, to: understand what has been already achieved in healthcare resilience; learn from the USA experience (i.e. enhance the American leadership); and fill in potential research gaps. Most of the HBN and HTMs have been locked and inaccessible to the public; it is only in April 2010 that these documents have become available and accessible as a result of the European Parliament and Council (2003) law Directive on the Re-use of Public Sector Information which forced all EU member states to make public sector publication accessible. American guiding documents, however, such as the Design Guide for Improving Hospital Safety in Earthquakes, Floods, and High Winds has been always accessible on the Federal Emergency Management Agency (FEMA, 2007) website. 


\subsection{Emergency response}

There is a common belief that emergencies will happen regardless of the level of preparedness, and individuals involved with the crisis will simply have to deal with the situation. This shows short vision and 'selfishness': although this statement is true vis-à-vis time passing, it is wrong vis-à-vis speed and efficiency of responding to emergencies. Healthcare resilience is not only for business continuity, but it is also a "social, moral and ethical necessity"; particularly in terms of public confidence (UNISDR, 2008). Considering healthcare resilience as 'business continuity' gives the impression that disaster induced emergencies and day-to-day operations are similar. For example, the lack of co-operation from water delivery staff who left an delivery for the Cheltenham Hospital on its doorstep rather than carrying it inside; and the refusal of private sector providers to attend the hospitals site demonstrate 'business responsibilities' but no morality; these actions resulted in extra work and stress to hospital staff (DH, 2008c). Laws, accountability and legal responsibility should be reviewed to allow extra flexibility to people to volunteer and help in emergencies; this will create a more positive ethos in a post disaster environment and will increase public confidence.

\section{Conclusions}

Healthcare facilities are one of the most complicated and critical type of facility in any country, their importance lies in dealing with the large number of injuries typically associated with large-scale disasters. Recent events and previous experiences have demonstrated the magnitude of natural disasters not only on health but also on the built healing environment. Despite their origins, natural disasters have similar impact on the continuity of medical services; therefore, learning lessons from other disasters would help not just in identifying gaps but also in adopting new techniques for healthcare resilience.

The complexity of healthcare facilities lies with: the number of systems that they host; the interconnectivity of these systems with each other and with external systems; and with the new care models that are being discussed. This complexity is reflected on healthcare facilities resilience and when combined with the considerable amount of $\mathrm{CO}_{2}$ emission, the resilience becomes more complicated. Consequently, climate change must be addressed comprehensively through fusing resilience and sustainability strategies into a more comprehensive strategy of adaptation.

Recent medical service disruptions caused by extreme weather events have highlighted the need to review current resilience strategies. The employment of in depth and independent investigations using modelling and simulation could provide evidence for decision makers to improve current strategies. The DH is urged to review its publication strategy and work closer with multi-disciplinary experts who will provide technical and tactical help and lessons learned from international best practices.

\section{References}

Achour, N. (2007), Estimation of Malfunction of a Healthcare Facility in Case of Earthquakes, Thesis $(\mathrm{PhD})$, Kanazawa University, Kanazawa, Japan.

Ahern, M. \& Kovas, S. (2006), "The Health Impacts of Floods", Few, R. \& Metthies, F. (Eds.), Flood Hazards \& Health, Earthscan, London.

Cabinet Office (2009), Strategic Framework and Policy Statement on Improving the Resilience of Critical Infrastructure to Disruption from Natural Hazards (Draft), Cabinet Office.

Cabinet Office (2010), Strategic Framework and Policy Statement on Improving the Resilience of Critical Infrastructure to Disruption from Natural Hazards, Cabinet Office.

Carvel, J. (2009), "Hospital services stretched after falls and road accidents in snow", Guardian, 2 February 2009, available online at http://www.guardian.co.uk/society/2009/feb/02/snow-nhsaccidents (accessed 25 January 2010). 
Chalko, T. (2001), "No second chance? Can Earth explode as a Result of Global Warming?" NU Journal of Discovery, Vol. 3 No. pp. 9p.

Chalko, T. (2008), "Earthquake Energy Rise on Earth", NU Journal of Discovery, Vol. 5 No. pp. 2p.

CRED (2008), Disaster Data: A Balanced Perspective, Brussels, Universite Catholique de Louvain.

DH (2008a), The Health Impact of Climate Change: Promoting Sustainable Communities, available online at http://www.dh.gov.uk/en/Publicationsandstatistics/Publications/DH_082690 (accessed on 12 June 2008).

DH (2008b), The Health Impact of Climate Change: Promoting Sustainable Communities - Guidance Document, Department of Health (DH).

DH (2008c), Report on the lessons learned from the summer 2007 flooding experiences, from an Estates and Facilities perspective, Crown.

EEA (2003), Mapping the impacts of recent natural disasters and technological accidents in Europe, Copenhagen, European Environment Agency (EEA).

EM-DAT (2008), Database- Country Profile, Centre for Research on Epidemiology of Disaster (CRED).

European Parliament and Council (2003), Directive on the re-use of public sector information, Europe's Information Society Thematic Portal.

FEMA (2007), Design Guide for Improving Hospital Safety in Earthquakes, Floods and High Winds, Washington D.C., Federal Emergency Management Agency (FEMA).

Gunn, S. W. A. (1995), "Health effects of earthquakes", Disaster Prevention and Management, Vol. 4 No. 5, pp. 6-10.

Hamilton, D. R., Gavagan, T., Smart, K., Weller, N., Upton, L. A., Havron, D. A., Fishkind, A., Persse, D., Shank, P., Shah, U. A. \& Mattox, K. (2009), "Houston's Medical Disaster Response to Hurricane Katrina: Part 2: Transitioning From Emergency Evacuee Care to Community Health Care", Annals of Emergency Medicine, Vol. 53 No. 4, pp. 515-527.

Hetzel, R. \& Hampel, A. (2006), "Long-Term Rates of Faulting Derived from Cosmogenic Nuclides and Short-term Variations caused by Glacial-Interglacial Volume Changes of Glaciers and Lakes", International Journal of Modern Physics B, Vol. 20 No. 3, pp. 261-276.

Jacoby, I. (1996), "Lessons for hospitals from the Midwest flood of 1993", Journal of Emergency Medicine, Vol. 14 No. 3, pp. 379-380.

JSWA (2002), Making Great Breakthroughs - All about the Sewage Works in Japan Japan Sewage Works Association (JSWA), Tokyo.

Mileti, D. (1999), Disasters by Design: A Reassessment of Natural Hazards in the United States, The Joseph Henry Press, Washington D.C.

Moore, M. (2009), "Hospitals cancel operations as snow chaos continues", Telegraph, 22 December 2009, available online at http://www.telegraph.co.uk/topics/weather/6865058/Hospitalscancel-operations-as-snow-chaos-continues.html (accessed 25 January 2010).

PAHO (2000), Principles of disaster mitigation in health facilities, PAHO, Washington D.C.

PAHO (2004), Guidelines for Vulnerability Reduction in the Design of New Health Facilities, Pan American Health Organisation (PAHO), Washington.

PAHO (2009), Safe Hospitals: A Collective Responsibility - A Global Measure of Disaster Reduction,

Peters, M. S. (1996), "Hospitals respond to water loss during the Midwest floods of 1993: Preparedness and improvisation", Journal of Emergency Medicine, Vol. 14 No. 3, pp. 345350.

Pitt, M. (2008), Learning Lessons from the 2007 Floods, London, Cabinet Office.

Sharma, R. (2002), "Gujarat earthquake causes major mental health problems", BMJ, Vol. 324 No. 7332 , pp. 259c.

Shinozuka, M., Ballantyne, D., Borcherdt, R., Buckle, I., O'Rourke, T. \& Schiff, A. J. (1995), The Hanshin-Awaji Earthquake of January 17, 1995: Performance of Lifelines, New York, National Center for Earthquake Engineering Research.

Sirbaugh, P. E., Bradley, R. N., Macias, C. G. \& Endom, E. E. (2002), "The Houston flood of 2001: The Texas Medical Center and lessons learned", Clinical Pediatric Emergency Medicine, Vol. 3 No. 4, pp. 275-283.

UN General Assembly (1994), International Decade for Natural Disaster Reduction, available online at http://www.un.org/documents/ga/res/49/a49r022.htm (accessed on 25 February 2009). 
Achour, N. \& Price, A.D.F. (2010) Resilience Strategies of Healthcare Facilities: Present and Future, International Journal of Disaster Resilience in the Built Environment (IJDRBE), 1(3), 264-276.

UNDP India (2008), Guidelines for Hospital Emergency Preparedness Planning: GOI-UNDP DRM Programme (2002-2008), Government of India (GOI) and United Nation Development Programme (UNDP), New Delhi.

UNISDR (2008), International Strategy for Disaster Reduction, available online at http://www.unisdr.org/eng/public aware/world camp/2008-2009/wdrc-2008-2009.html (accessed on 12 June 2008).

WHO (2007), "Risk Reduction in the Health Sector and Status of Progress", Disaster Risk Reduction in the Healthcare Sector- Thematic Workshop, 6 June 2007, Geneva.

Zhang, L., Li, H., Carlton, J. R. \& Ursano, R. (2009), "The injury profile after the 2008 earthquakes in China", Injury, Vol. 40 No. 1, pp. 84-86. 